\title{
Impact of nerve stimulator-guided obturator nerve block on the short-term outcomes and complications of transurethral resection of bladder tumour: A prospective randomized controlled study
}

\author{
Deniz Bolat, MD; Ozgu Aydogdu, MD; Zeki Tuncel Tekgul, MD; Salih Polat, MD; Tarik Yonguc, MD; \\ Ibrahim Halil Bozkurt, MD; Volkan Sen, MD; Onur Okur, MD
}

Izmir Bozyaka Training and Research Hospital, Department of Urology, Izmir, Turkey

Cite as: Can Urol Assoc J 2015;9(11-12):E780-4. http://dx.doi.org/10.5489/cuai.3149

Published online November 4, 2015.

\section{Abstract}

Introduction: In this prospective randomized controlled study, we investigated the efficacy of obturator nerve block (ONB) on adductor muscle spasm and related short-term outcomes and complications in patients who underwent transurethral resection of lateral wall-located bladder tumours (TURBT).

Methods: Between July 2014 and February 2015, 70 patients scheduled to undergo TUR of lateral bladder wall tumours were enrolled in the study. All patients were preoperatively evaluated by cystoscopy and imaging tools and selected according to localized tumours on the lateral bladder wall. Patients were randomly allocated to Group SA (35 patients who underwent only spinal anesthesia) and Group ONB (35 patients who underwent spinal anesthesia combined with ONB by the nerve stimulator). An independent observer, blinded to the approach, evaluated the obturator signs, including adductor muscle contraction, bladder perforation, and completeness of the resection during the TURBT procedure. Results: The differences between groups regarding mean operation time, tumour size, and number were not statistically significant $(p>0.05)$. Adductor muscle contraction was detected in $40 \%$ of patients in Group SA and $11.4 \%$ in Group ONB. This difference was statistically significant $(p=0.021)$. Complete bladder perforation was detected in 2 patients in Group SA, whereas no perforation was observed in Group ONB. There was no case of severe bleeding in both groups.

Conclusions: We found that ONB performed after spinal anesthesia was effective in preventing intraoperative complications due to adductor muscle spasm while performing TURBT. Our study limitations include its small sample size, since we only enrolled patients with primary lateral wall-localized bladder tumour. Also, we excluded patients who underwent bipolar TURBT.

\section{Introduction}

Bladder cancer is the ninth most commonly diagnosed cancer worldwide, with more than 380000 new cases a year. ${ }^{1}$ Transurethral resection of bladder tumours (TURBT) is a crucial procedure in its diagnosis and treatment. ${ }^{2}$

In the TURBT procedure, the obturator nerve passes through the obturator foramen of the pubis and innervates the adductor muscles of the thigh. It originates from the lumbar plexus of L2 to L4 and contains both motor and sensory nerve fibres. Within the pelvic cavity, it runs close to the prostatic urethra, bladder neck, and inferolateral bladder wall. ${ }^{3}$

Rodriguez and colleagues found that $46.8 \%$ of all bladder tumours are located at the lateral wall of the bladder. ${ }^{4}$ When the bladder is distended with irrigation fluid, the obturator nerve is very close to the lateral bladder wall. While performing TURBT of the lateral wall-located bladder tumours, one can perform an electrosurgical resection to stimulate the adjacent obturator nerve leading to adductor contraction and leg jerking. ${ }^{3}$ Involuntary movement of the legs due to adductor spasm can cause incomplete tumour resection, bladder perforation, and extravesical dissemination of the cancer cells and vascular injuries. ${ }^{3,5}$

In this prospective randomized controlled study, we investigated the effect of obturator nerve block (ONB) on adductor spasm and short-term complication rates in the patients who underwent TURBT for bladder tumours on the lateral bladder wall.

\section{Methods}

In this prospective, randomized study, we enrolled 70 patients to this study. Each patient had an American Society of Anesthesiologists (ASA) physical status I to IV and were scheduled to undergo TUR of inferolateral bladder wall tumours from July 2014 to February 2015. Approval was obtained 
from our instutional ethical committee and written informed consent was obtained from all study participants.

All patients were preoperatively evaluated by cystoscopy and imaging tools, such as ultrasound, and computed tomography. Patients were selected according to localized tumours on the inferolateral bladder wall. We excluded patients with a known allergy to local anesthetics and patients with previous surgery or scars in the ONB region, coagulopathy, pregnancy and neuromuscular disease.

In the operating room, patients were monitored by continuous electrocardiography, non-invasive blood pressure, and pulse oximetry. Patients were pre-loaded with $10 \mathrm{~mL} /$ $\mathrm{kg}$ of $0.9 \%$ isotonic solution intravenously. To maintain the oxygenation, patients received $4 \mathrm{~L} / \mathrm{min}$ of oxygen via a facemask. All patients were pre-medicated with 1 to $2 \mathrm{mg}$ midazolam intravenously before the spinal anesthesia. Using shuffled sealed envelopes with anesthesia allocations inside, we randomly allocated patients to the spinal anesthesia group (Group SA, $\mathrm{n}=35$ ) or the spinal anesthesia combined with ONB group (Group ONB, $\mathrm{n}=35$ ).

In Group SA, spinal anesthesia was performed with 10 to $15 \mathrm{mg} 0.5 \%$ hyperbaric bupivacaine by $25 \mathrm{G}$ Quincke needle at L3L4 or L4L5 space with patients in the seated position. Afterwards, pateints were immediately placed into the supine position and the sensory blockade was checked with a pin-prick test. When the block reached the T10 level, patients were placed into the lithotomy position and the surgery was started.

In the case of Group ONB, ONB was performed unilaterally or bilaterally according to tumour position following verification of the level of spinal anesthesia with the patient in lithotomy position. A 10-mm Teflon-insulated needle (21G Stimuplex A, B. Braun Melsungen AG, Germany) using a nerve stimulator (B. Braun Melsungen AG, Germany) was inserted perpendicularly $2 \mathrm{~cm}$ inferiorly and $2 \mathrm{~cm}$ laterally to the pubic tubercle. As per the traditional approach, we adjusted the current power of the nerve stimulator to 1.5 to $2 \mathrm{~mA}$ and current periods to $0.1 \mathrm{~ms}$. Consequently, the needle was inserted through the skin to the inferior ramus of the pubic bone. It was then slightly pulled back and redirected anterolaterally, contacting the nerve in a depth of 2 to $4 \mathrm{~cm} ; 10 \mathrm{~mL} 0.25 \%$ levobupivacaine was administered at 0.3 to $0.5 \mathrm{~mA}$ when contraction was observed at the adductor muscle groups and after aspiration was negative. ${ }^{6}$

Surgery was initiated after 10 minutes following injection. The same anesthesia staff performed the ONBs and the same urologist, blinded to the ONB, operated on patients in both groups and evaluated the obturator signs. No additional techniques were used to prevent adductor muscle contractions during surgery other than ONB.

The TURBT procedure was performed by a 26 -French monopolar resectoscope with 30-degree optic and glycine irrigation solution. If the adductor spasm was severe enough to disturb the surgeon's resection, it was deemed a severe adductor muscle contraction. However, if there was a adductor muscle spasm but not severe enough to disturb the surgeon, it was deemed a moderate adductor muscle contraction.

Statistical analysis was performed using SPSS (SPSS Inc, Chicago, IL) version 21.0. Descriptive data were given as mean \pm standard deviation. Continuous variables were compared with an independent sample t-test, and categorical variables were compared with the Fischer's exact test. Statistical significance was set at $p<0.05$.

\section{Results}

We tallied patient demographics, including age, weight, male/female ratios and ASA scores (Table 1). The differences between the groups regarding mean operation time, tumour size, and tumor number were not statistically significant (Table 2).

Adductor muscle contraction was detected in $40 \%$ of the patients in Group SA and $11.4 \%$ in Group ONB and this difference was statistically significant $(p=0.021)$. While severe degree adductor spasm was observed in $17.1 \%$ of patients in Group SA, this rate was $2.8 \%$ in Group ONB.

Subserosal injury was observed $31.4 \%$ and $11.4 \%$ in Groups SA and ONB, respectively. In 2 patients (5.7\%) in Group SA, complete bladder perforations were detected, whereas no complete perforations were observed in Group ONB. The perforations in Group SA were extrapertoneally and patients were managed conservatively. Complete tumour resection was performed in $77.1 \%$ and $97.1 \%$ of patients in Groups SA and ONB, respectively $(p=0.028)$ (Table 3). Patients with incomplete resection underwent reoperation under general anesthesia 6 weeks later. There was no bleeding requiring transfusion in both groups.

\section{Discussion}

Sudden adductor muscle spasm can occur when the obturator nerve is directly stimulated by the electrical current trans-

\begin{tabular}{lccc}
\hline Table 1. Patient demographics & & \\
\hline & $\begin{array}{c}\text { Group SA } \\
(\mathbf{n}=35)\end{array}$ & $\begin{array}{c}\text { Group ONB } \\
(\mathbf{n}=35)\end{array}$ & $\boldsymbol{p}$ value \\
\hline Age, years, mean \pm SD & $67.7 \pm 10.5$ & $70.1 \pm 12.2$ & $0.398^{*}$ \\
Weight, kg, mean \pm SD & $72.1 \pm 10.9$ & $70.9 \pm 15.2$ & $0.712^{*}$ \\
Gender, male/female & $29 / 6$ & $30 / 5$ & $0.743^{*}$ \\
ASA score, n (\%) & & & $0.680^{\dagger}$ \\
1 & $3(8.6)$ & $2(5.7)$ & \\
2 & $24(68.6)$ & $22(62.9)$ & \\
3 & $8(22.9)$ & $10(28.6)$ & \\
4 & - & $1(2.9)$ & \\
\hline
\end{tabular}

*Independent sample t-test; ${ }^{\dagger}$ Fischer's exact test; SD: standard deviation; ASA: American Society of Anesthesiologists; ONB: obturator nerve block; SA: spinal anesthesia. 
Table 2. Patient perioperative outcomes

\begin{tabular}{lccc} 
& $\begin{array}{c}\text { Group SA } \\
(\mathbf{n}=35)\end{array}$ & $\begin{array}{c}\text { Group ONB } \\
(\mathbf{n}=\mathbf{3 5})\end{array}$ & p value \\
\hline $\begin{array}{l}\text { Operation time, } \\
\text { minutes, mean } \pm \text { SD }\end{array}$ & $29.6 \pm 12.0$ & $29.1 \pm 13.3$ & $0.888^{*}$ \\
$\begin{array}{l}\text { Tumour size, mm, } \\
\text { mean } \pm \text { SD }\end{array}$ & $3.6 \pm 1.9$ & $3.9 \pm 2.8$ & $0.692^{*}$ \\
$\begin{array}{l}\text { Tumour number, n, } \\
\text { mean } \pm \text { SD }\end{array}$ & $1.8 \pm 1.3$ & $2.1 \pm 1.8$ & $0.359^{*}$ \\
\hline *Independent sample t-test; SD: standard deviation; ONB: obturator nerve block; SA: spinal \\
anesthesia.
\end{tabular}

mitted by the resectoscope. This is especially true when the surgeon is operating at the lateral wall of the bladder, where the obturator nerve is close during its intrapelvic course. ${ }^{7}$ Prentiss and colleagues reported a $20 \%$ incidence of severe adductor muscle contraction in patients undergoing TUR for large intra-urethral prostatic adenomas and laterally located bladder tumours. ${ }^{8}$ Tatlısen and Sofikerim demonstrated that 63 of 114 patients experienced adductor spasm elicited by obturator stimulation during TURBT. ${ }^{9}$

Different strategies, such as partial filling of the bladder during resection, reducing the intensity of the current of the resectoscope, resecting the tumour on thinner slices, using bipolar or laser resectoscopes, and using general anesthesia with muscle relaxants, are adopted to avoid complications during surgery. ${ }^{10,11}$ Bipolar and laser systems are expensive and not available at many centres. The use of general anesthesia and muscle relaxants for TURBT are not recommended, because most patients with bladder tumour are heavy smokers (about $50 \%$ of cases). ${ }^{12,13}$ In addition, the median age at diagnosis for patients (men and women) is 73 years, so cardiopulmonary conditions are serious limitations for general anesthesia in these patients. ${ }^{14}$ In many patients, spinal anesthesia is a better choice in TURBT. ${ }^{15}$ In our clinic, spinal anesthesia is the standard anesthetic technique for TURBT. General anesthesia is given only to uncooperative patients, patients failing spinal anesthesia or when adductor spasms occur. However, spinal anesthesia is also ineffective in preventing the adductor spasm. Patel and colleagues divided patients scheduled for TURBT into spinal anesthesia and spinal anesthesia with ONB groups. They found that almost all patients in the spinal anesthesia group developed adductor spasm of varying degree disturbing the surgeon. ${ }^{16}$ In our study, moderate and severe adductor muscle spasms were observed in $22.9 \%$ and $17.1 \%$, respectively, of patients in the spinal anesthesia group, and in $8.6 \%$ and $2.8 \%$ of patients in the ONB group.

Literature search yields many studies showing the efficacy of ONB in preventing the adductor muscle contraction and related complications during the resection of the lateral wall localized bladder tumours. ${ }^{3,4,9,16}$ ONB can be performed using multiple techniques with various success rates. The success rate of the transperineal ONB using the "blind ana-

\begin{tabular}{|c|c|c|c|}
\hline & $\begin{array}{c}\text { Group SA } \\
(n=35)\end{array}$ & $\begin{array}{c}\text { Group ONB } \\
(n=35)\end{array}$ & $p$ value \\
\hline $\begin{array}{l}\text { Adductor muscle } \\
\text { contraction, } \mathrm{n}(\%)\end{array}$ & & & $0.021 *$ \\
\hline No & $21(60)$ & $31(88.6)$ & \\
\hline Moderate & $8(22.9)$ & $3(8.6)$ & \\
\hline Severe & $6(17.1)$ & $1(2.8)$ & \\
\hline Bladder perforation, $\mathrm{n}(\%)$ & & & $0.680 *$ \\
\hline No & $22(62.9)$ & $31(88.6)$ & \\
\hline Subserosal injury & $11(31.4)$ & $4(11.4)$ & \\
\hline Complete perforation & $2(5.7)$ & - & \\
\hline Complete resection, $\mathrm{n}(\%)$ & & & $0.028 *$ \\
\hline Yes & $27(77.1)$ & $34(97.1)$ & \\
\hline No & $8(22.9)$ & $1(2.9)$ & \\
\hline
\end{tabular}

tomic approach" is 83.8 to $85.7 \%$. 5,9,17 There are many ways to increase the efficacy of ONB. The success rate is $84 \%$ to $96 \%$ using the "nerve stimulation technique." ${ }^{16-19}$ In our study we used the "nerve stimulation technique," described by Parks and Kennedy in $1967 .{ }^{6}$ Using this technique, our success rate was $88.6 \%$ and this rate was attributed to the accessory obturator nerve or its abnormal branching. An accessory obturator nerve is present in about $10 \%$ to $30 \%$ of the population. ${ }^{6,20}$ It lies parallel to the main obturator nerve along the medial side of the psoas muscle, passing ventral to the superior pubic ramus behind the femoral vein and joins the anterior part of the main obturator nerve. It is debatable whether stimulation of the accessory obturator nerve can occur during TUR. ${ }^{5}$

Failure of the blockade can also be due to operator error. In experienced hands, location of the obturator nerve may be easy and the blockade can be done successfully. Different blockade techniques have been developed to minimize operator-dependent failure. Given the complex anatomy in the pelvic region, the use of traditional methods that rely on anatomical landmarks to identify and block the obturator nerve carries the risk of failure or incomplete blockage. ${ }^{21}$ In these situations, transvesical ONB can be considered. This nerve block may be performed by the guide of nerve stimulation or anatomic landmarks. ${ }^{22-24}$ Moreover, more recent studies reported that the use of an ultrasound in regional anesthesia is associated with higher success rates as $93 \%$ to $97.2 \%$ in ultrasound-guided ONB procedures. ${ }^{21,25}$ Akkaya and colleagues demonstrated a new methodological approach based on a sono-anatomic study to visualize the obturator nerve. They reported patient satisfaction rates as high as $93 \% .{ }^{26}$ These rates show that ultrasound-guided ONB is more successful than a nerve stimulator technique.

Adductor muscle contraction and leg jerking due to the obturator nerve stimulation during TURBT can lead to bleeding, incomplete resection of tumour, hematoma, bladder 
perforations, and extravesical spread of tumour. These conditions may increase patient morbidity and mortality. ${ }^{5,9,16}$ In our study, complete bladder perforation was observed in 2 patients in Group SA, while no perforation was seen in Group ONB. No severe bleeding was detected in both groups. Residual tumour tissue following TURBT increased recurrence rates and shortened the tumour-free interval. Jancke and colleagues showed that $26 \%$ of patients had residual tissue following complete resection of their nonmuscle invasive bladder tumours and these patients suffered from significantly higher recurrence rates when compared to the others. ${ }^{27}$ Tekgül and colleagues reported overall recurrence rates of $27.8 \%$ and $18.8 \%$ in patients with spinal anesthesia only and in combination with ONB, respectively. However, this difference was not statistically significant. ${ }^{28}$ In our study, we did not investigated recurrence-free rates. As well as, complete resection rates significantly increased after the ONB. Tumours were incompletely resected in $22.9 \%$ and $2.9 \%$ of the patients in Groups SA and ONB, respectively. Patients with incomplete resection underwent re-operation under general anesthesia 6 weeks later.

Although ONB with a nerve stimulator should be considered in association with spinal anesthesia in patients who are at high risk for general anesthesia, it is quite an invasive approach, technically difficult, and requires a longer needle. The direction of the needle is toward the pelvic contents, which increases the chances of complications. ${ }^{10}$ For example, poor nerve blockade can rarely lead to intraoperative obturator jerks that can cause bladder perforation. ${ }^{3}$ In addition, the obturator artery accompanies the obturator nerve through the foramen. Damage to the artery and arterial bleeding can occur there when advancing the needle. Cesur and colleagues reported a case of difficulty localizing the nerve and a hematoma. ${ }^{29}$ Akata and colleagues reported that an incomplete ONB led to obturator jerk, which caused damage to the obturator artery and major bleeding. ${ }^{5}$ In our study no complications were observed due to the ONB.

Our study limitations include its small sample size, since we only enrolled patients with primary lateral wall-localized bladder tumour. Also, we excluded patients who underwent bipolar TURBT.

\section{Conclusion}

ONB with a nerve stimulator in combination with spinal anesthesia is an effective and safe way to prevent adductor muscle contraction and related intraoperative complications in patients during TURBT. Bigger, prospective, randomized studies are needed to support our study.

Competing interests: The authors declare no competing financial or personal interests.
This paper has been peer-reviewed.

\section{References}

1. Siegel R, Naishadham D, Jemal A. Cancer statistics, 2013. CA Cancer I Clin 2013;63:11-30. http:// dx.doi.org/10.3322/caac.21166

2. Babjuk $M$, Burger $M$, Zigeuner $R$, et al. EAU guidelines on non-muscle-invasive urethelial carcinoma of the bladder: Update 2013. Eur Urol 2013;64:639-53. http://dx.doi.org/10.1016/i.eururo.2013.06.003

3. Kuo JY. Prevention of obturator jerk during transurethral resection of bladder tumor. JTUA 2008;19:27-31.

4. García Rodríguez J, Jalón Monzón A, González Alvarez RC, et al. An alternative technique to prevent obturator nerve stimulation during lateral bladder tumours transurethral resection [in Spanish]. Actas Urol Esp 2005;29:445-7. http://dx.doi.org/10.1016/S0210-4806(05)73273-3

5. Akata T, Murakami J, Yoshinaga A. Life-threatening haemorrhage following obturator artery injury during transurethral bladder surgery: A sequel of an unsuccessful obturator nerve block. Acta Anaesthesiol Scand 1999;43:784-8. http://dx.doi.org/10.1034/i.1399-6576.1999.430717.x

6. Parks CR, Kennedy WF Jr. Obturator nerve block: A simplified approach. Anesthesiology 1967;28:775-8. http://dx.doi.org/10.1097/00000542-196707000-00033

7. So PC. Two case reports of obturator nerve block for transurethral resection of bladder tumour. Hong Kong Med J 2004;10:57-9.

8. Prentiss RJ, Harvey GW, Bethard WF, et al. Massive adductor muscle contraction in transurethral surgery, cause and prevention in development of new electrical circuitry. J Urol 1965;93:263-71.

9. Tatlisen A, Sofikerim M. Obturator nerve block and transurethral surgery for bladder cancer. Minerva Urol Nefrol 2007;59:137-41.

10. Moningi S, Durga P, Ramachandran G, et al. Comparison of inguinal versus classic approach for obturator nerve block in patients undergoing transurethral resection of bladder tumors under spinal anesthesia. $J$ Anaesthesiol Clin Pharmacol 2014;30:41-5. http://dx.doi.org/10.4103/0970-9185.125702

11. Kramer MW, Bach $T$ Wolters $M$, et al. Current evidence for transurethral laser terapy of non-muscle invasive bladder cancer. World J Urol 201 1;29:433-42. http://dx.doi.org/10.1007/s00345-01 1-0680-5

12. Burger $M$, Catto JW, Dalbagni $G$, et al. Epidemiology and risk factors of urothelial bladder cancer. Eur Urol 2013;63:234-41. http://dx.doi.org/10.1016/i.eururo.2012.07.033

13. Freedman ND, Silverman DT, Hollenbeck AR, et al. Association between smoking and risk of bladder cancer among men and women. JAMA 2011;306:737-45. http://dx.doi.org/10.1001/jama.2011.1142

14. Prout GR Jr, Wesley MN, Yancik R, et al. Age and comorbidity impact surgical therapy in older bladder carcinoma patients: A population-based study. Cancer 2005;104:1638-47. http://dx.doi.org/10.1002/ cncr. 21354

15. Moulaert $P$, Verbaeys $A$, De Brock M. Obturator nerve block in preventing bladder perforation during endoscopic transurethral bladder surgery. Acta Urol Belg 1988;56:523-5.

16. Patel D, Shah B, Patel BM. Obturator nerve block for bladder tumours. Indian J Anaesth 2004:48:47-9.

17. Augspurger RR, Donohue RE. Prevention of obturator nerve stimulation during transurethral surgery. J Urol 1980;123:170-2.

18. Jo YY, Choi E, Kil HK. Comparison of the success rate of inguinal approach with classical pubic approach for obturator nerve block in patients undergoing TURB. Korean J Anesthesiol 201 1;61:143-7. http:// dx.doi.org/10.4097/kjae.2011.61.2.143

19. Kakinohana $M$, Taira $Y$, Saitoh $T$, et al. Interadductor approach to obturator nerve block for transurethral resection procedure: Comparison with traditional approach. J Anesth 2002;16:123-6. http://dx.doi. org/10.1007/s005400200006

20. Woodburne RT. The accesory obturator nerve and the innervation of the pectineus muscle. Anat Rec 1960;136:367-9. http://dx.doi.org/10.1002/or.1091360303

21. Thallaj A, Rabah D. Efficacy of ultrasound-guided obturator nerve block in transurethral surgery. Saudi J Anaesth 2011;5:42-4. http://dx.doi.org/10.4103/1658-354X.76507

22. Mihara $\mathrm{T}$, Itoh $\mathrm{H}$, Hashimoto $\mathrm{K}$, et al. Trans-resectoscope stimulation predicts the need to block adductor response during bladder tumor resection. Anesth Analg 2013;117:740-4. http://dx.doi.org/10.1213/ ANE.0b013e3182a07063

23. Khorrami MH, Javid A, Saryazdi $H$, et al. Transvesical blockade of the obturator nerve to prevent adductor contraction in transurethral bladder surgery. J Endouro/ 2010;24:1651-4. http://dx.doi.org/10.1089/ end.2009.0659

24. Khorrami $M$, Hadi $M$, Javid $A$, et al. A comparison between blind and nerve stimulation guided obturator verve block in transurethral resection of bladder tumor. J Endourol 2012;26:1319-22. http://dx.doi. org/10.1089/end.2012.0037

25. Lee $\mathrm{SH}$, Jeong $\mathrm{CW}$, Lee $\mathrm{HJ}$, et al. Ultrasound guided obturator nerve block: A single interfascial injection technique. J Anesth 2011;5:923-6. http://dx.doi.org/10.1007/s00540-011-1228-y 
Bolat et al.

26. Akkaya T, Ozturk E, Comert A, et al. Ultrasound -guided obturator nerve block: A sonoanatomic study of a new methodological approach. Anesth Analg 2009;108:1037-41. http://dx.doi.org/10.1213/ ane.0b013e3181966f03

27. Jancke $G$, Rosell J, Jahnson $S$. Residual tumor in the marginal resection after a complete transurethral resection is associated with local recurrence in $\mathrm{Ta} / \mathrm{Tl}$ urinary bladder cancer. Scand J Urol Nephrol 2012;46:343-7. http://dx.doi.org/10.3109/00365599.2012.684700

28. Tekgül ZT, Divrik RT, Turan M, et al. Impact of obturator nerve block on the short-term recurrence of superficial bladder tumors on the lateral wall. Urol J 2014;11:1248-52.
29. Cesur $M$, Erdem AF, Alici HA, et al. The role of succinylcholine in the prevention of the obturator nerve reflex during transurethral resection of bladder tumors. Saudi Med J 2008;29:668-71.

Correspondence: Dr. Deniz Bolat, lzmir Bozyaka Training and Research Hospital, Department of Urology, Izmir, Turkey; drbolat@hotmail.com 